\title{
CÁLCULO DO PERFIL TÉRMICO DE UM MANDRIL USADO NA LAMINAÇÃO DE TUBOS SEM COSTURA ATRAVÉS DO MÉTODO DE DIFERENÇAS FINITAS*
}

\author{
Lis Nunes Soares ${ }^{1}$ \\ Rodrigo Venâncio da Silva² \\ Laura Silva Macedo Lima ${ }^{3}$ \\ André Amaral Ribeiro ${ }^{4}$
}

\section{Resumo}

A Vallourec Tubos do Brasil é uma siderúrgica integrada com produção de tubos de aço sem costura. A qualidade e o acabamento superficial dos tubos estão diretamente relacionados com o processo de laminação pelo qual eles passam. Um fator extremamente importante para um bom processo de laminação é uma boa lubrificação da peça de laminação, o mandril. Durante o processo de laminação, o mandril passa por várias etapas além da lubrificação, incluindo etapas de aquecimento e resfriamento, que se repetem em ciclos de laminação. Um dos principais parâmetros do processo de produção que influenciam a lubrificação do mandril é justamente o perfil térmico e a temperatura superficial do mesmo. O perfil térmico do mandril afeta a aderência do lubrificante em sua superfície. Visando a melhor compreensão do processo, esse trabalho tem como objetivo propor um modelo matemático em diferenças finitas que descreva a evolução do perfil térmico do mandril durante o processo de laminação de tubos sem costura. $O$ mesmo modelo matemático é validado através de engenharia reversa. A proposta do modelo matemático é ser usado na análise de possíveis métodos de pré-aquecimento de mandris antes da lubrificação, diminuindo ou eliminando assim possível sucateamento de peças e paradas da linha de produção por esse motivo.

Palavras-chave: Mandril; Laminação; Diferenças Finitas; Transferência de Calor.

\section{THERMAL PROFILE CALCULATION OF A MANDREL USED IN CONTINUOUS TUBE ROLLING MILL BY FINITE DIFFERENCES ANALISYS}

\begin{abstract}
Vallourec Tubes of Brazil is an integrated steel mill for the production of steel tubes. The steel tubes quality and surface finishing are directly related to the rolling process applied on them. It is extremely important, for a good rolling process, a good lubrication of the rolling tool, the mandrel, which is introduced through the tube, finishing its interior surface. During the rolling process, the mandrel passes through several stages besides lubrication, including heating and cooling stages, which are repeated throughout the rolling cycles. One of the most influent rolling process parameters on mandrel lubrication is its thermal profile along its diameter, highlighting its surface temperature. Mandrel thermal profile affects the lubricant adherence on its surface. The mathematical model is also to be validated through reverse engineering. The final goal of this work is to be useful on possible analyses on pre-heating mandrel methods to be implanted before lubrication, diminishing or even eliminating mandrel or tube scrapping and production line stoppage due to cold mandrel problems.
\end{abstract}

Keywords: Mandrel; Rolling Mill, Finite Differences, Heat Transfer.

1 Engenheira Mecânica, Doutora, Gerência de Utilidades e Eficiência Energética, Vallourec Tubos do Brasil S.A., Belo Horizonte, MG, Brasil.

2 Estudante de graduação em Engenharia Mecânica, PUC-MG, Gerência de Utilidades e Eficiência Energética, Vallourec Tubos do Brasil S.A., Belo Horizonte, MG, Brasil.

3 Estudante de graduação em Engenharia Mecânica, UFMG, Gerência de Utilidades e Eficiência Energética, Vallourec Tubos do Brasil S.A., Belo Horizonte, MG, Brasil.

4 Estudante de graduação em Engenharia Química, UFMG, Gerência de Utilidades e Eficiência Energética, Vallourec Tubos do Brasil S.A., Belo Horizonte, MG, Brasil.

* Contribuição técnica ao $35^{\circ}$ Seminário de Balanços Energéticos Globais e Utilidades e $29^{\circ}$ Encontro de Produtores e Consumidores de Gases Industriais, 13 a 15 de agosto de 2014, São Paulo, SP, Brasil. 


\section{INTRODUÇÃO}

O processo de laminação contínua na VBR acontece em várias etapas. Uma dessas etapas consiste na introdução de uma peça cilíndrica metálica, chamada de mandril, na lupa ainda quente, que seria o tubo de aço ainda em processo de produção.

Para um bom processo de laminação no laminador contínuo na VBR, é extremamente importante uma boa lubrificação do mandril. Essa lubrificação acontece por meio de jatos de lubrificante, composto de água e grafite, na superfície do mandril ao longo de seu comprimento.

A função da água no lubrificante é manter o grafite na superfície do mandril enquanto evapora. Sem a presença de água no lubrificante, o grafite não iria se fixar sobre o mandril. No entanto, se não ocorrer a secagem da água no devido tempo, a mesma começa a escorrer pela superfície da ferramenta, lavando o grafite. A lubrificação ruim do mandril vem a gerar tensões na passagem do mesmo junto com a lupa no laminador. Tudo isso interfere no fluxo de massa no laminador contínuo gerando problemas de qualidade no tubo, produto final, e/ou defeitos no mandril como barriga, parede grossa, rugosidade, calo de mandril, buraco interno, bolsa interna, ondulação interna, etc. Esses defeitos tem impacto na produção não só pelo sucateamento de peças (lupas e mandris), mas também pelas paradas causadas devido a defeitos das peças e/ou na linha, gerando assim prejuízos não só por sucateamento, mas também por manutenção e tempo de equipamento ocioso.

Empiricamente, o Departamento de Laminação Contínua da VBR observou que o problema de secagem imprópria da água do lubrificante, levando a uma lubrificação ruim, acontece principalmente no início da produção, quando o mandril está frio. Durante a passagem do mandril pela linha de produção, o mesmo é aquecido por entrar em contato com a lupa quente que se encontra a uma temperatura de aproximadamente $1100^{\circ} \mathrm{C}$. Após alguns ciclos de laminação o mandril já absorveu energia suficiente para que a secagem da água do lubrificante ocorra devidamente. Empiricamente, a equipe da laminação observa que a secagem ocorre bem, a partir do terceiro ciclo de laminação e com o mandril apresentando uma temperatura superficial de aproximadamente $80^{\circ} \mathrm{C}$. No entanto, se o mandril permanecer na linha de produção por muito tempo, ele absorve energia em demasia e sua temperatura superficial excede $100^{\circ} \mathrm{C}$, levando a água do lubrificante a entrar em ebulição em contato com ele. A ebulição é indesejável devido ao fato das bolhas, ao estourarem, causarem buracos na lubrificação e assim também levando aos prejuízos apresentados acima.

Em razão de melhorar o processo de laminação contínua na VBR, está sendo estudada a implantação de um método de pré-aquecimento de mandris, nos primeiros ciclos do processo. Para tanto, esse trabalho tem como objetivo o desenvolvimento de um modelo matemático que descreva o perfil térmico do mandril ao longo da linha de produção e através disso, calcular a quantidade necessária de energia a ser cedida ao mandril no pré-aquecimento para uma boa secagem da água do lubrificante.

\section{MATERIAIS E MÉTODOS}

Para melhor entendimento do problema, criou-se um modelo matemático que descreve o que acontece na linha de produção atualmente. Observou-se que o processo é transiente nos primeiros ciclos da laminação, período de interesse do estudo. Devido às condições de contorno complexas do problema, foi escolhida uma

* Contribuição técnica ao $35^{\circ}$ Seminário de Balanços Energéticos Globais e Utilidades e $29^{\circ}$ Encontro de Produtores e Consumidores de Gases Industriais, 13 a 15 de agosto de 2014, São Paulo, SP, Brasil. 
abordagem por métodos numéricos e o modelo matemático foi construído então, em diferenças finitas implícitas em uma plataforma de Excel $^{\circledR}$. Como previsto em Incropera and DeWitt [1], tal método implica na separação do objeto de estudo em pequenas regiões nodais e a aplicação de balanços de energia em cada nó. Os balanços de energia levam a equações diferenciais que são aproximadas por equações lineares. A solução do problema se deve à solução das equações lineares de cada região nodal como um sistema de equações.

Para a aplicação do método de diferenças finitas (MDF), a condução de calor no mandril foi considerada como unidimensional e radial. Logo, os nós foram definidos ao longo do raio do mandril, indo do nó zero no centro (raio $=0$ ) até o nó $n$ na superfície. $O$ incremento no espaço $\Delta r$ foi considerado $1 \mathrm{~mm}$ e o incremento no tempo $\Delta t$ foi considerado 1 segundo. O tratamento das equações (1), (2), (3) e (4), apresentadas na Tabela 1 levam às equações do MDF, também mostradas na Tabela 1, (5),(6), e (7).

Tabela 1. Equações

\begin{tabular}{|c|c|c|}
\hline Equações & Descrição & Número \\
\hline$\dot{\mathrm{E}}_{\text {acumulada }}=\dot{\mathrm{E}}_{\text {entrada }}-\dot{\mathrm{E}}_{\text {saída }}+\dot{\mathrm{E}}_{\text {gerada }}$ & Balanço de Energia & $(1)$ \\
\hline$\dot{\mathbf{q}}_{\text {cond }}+\dot{\mathbf{q}}_{\text {conv }}+\dot{\mathbf{q}}_{\text {rad }}=\rho \cdot \mathbf{c}_{\mathbf{p}} \cdot V \cdot \frac{\partial \mathrm{T}}{\partial \mathrm{t}}$ & $\begin{array}{l}\text { Balanço de Energia } \\
\text { com os fluxos térmicos }\end{array}$ & (2) \\
\hline $\mathrm{Fo}_{0}=\frac{\alpha \cdot \Delta \mathrm{t}}{\Delta \mathrm{r}^{2}}$ & Número de Fourier & (3) \\
\hline $\mathrm{Bi}=\frac{\mathrm{h} \cdot \Delta \mathrm{r}}{\mathrm{k}}$ & Número de Biot & (4) \\
\hline$(1+2 \mathrm{Fo}+2 \mathrm{FoBi}) \mathrm{T}_{n}^{\mathrm{p}+1}-2 \mathrm{FoT}_{\mathrm{n}-1}^{\mathrm{p}+1}=2 \mathrm{FoBiT} \mathrm{T}_{\infty}+\mathrm{T}_{\mathrm{n}}^{\mathrm{p}}$ & $\begin{array}{l}\text { Equação do nó n } \\
\text { (superfície) }\end{array}$ & (5) \\
\hline$(1+2 F o) T_{n}^{p+1}-F o\left(T_{n-1}^{p+1}+T_{n+1}^{p+1}\right)=T_{n}^{p}$ & $\begin{array}{l}\text { Equações dos nós } 1 \text { à } \\
n-1\end{array}$ & (6) \\
\hline$(1+2 \mathrm{Fo}) \mathrm{T}_{\mathrm{n}}^{\mathrm{p}+1}-2 \mathrm{FoT}_{1}{ }^{\mathrm{p}+1}=\mathrm{T}_{\mathrm{n}}^{\mathrm{p}}$ & $\begin{array}{l}\text { Equação do nó } 0 \\
\text { (centro) }\end{array}$ & (7) \\
\hline $\mathrm{E}_{\text {acumulada }}=\mathrm{m} \cdot \mathrm{c}_{\mathrm{p}} \cdot \Delta \mathrm{T}$ & $\begin{array}{l}\text { Cálculo da energia } \\
\text { interna do mandril }\end{array}$ & (8) \\
\hline
\end{tabular}

Equações do balanço de energia e do método de diferenças finitas implícito.

A aplicação das equações (5), (6), e (7) da Tabela 1 acima, nos respectivos nós como descritos também na Tabela 1, levam a um sistema de equações lineares. Do sistema de equações criado, pode-se montar uma matriz $[A]$ dos coeficientes do lado esquerdo das equações, que multiplica um vetor [T] contendo as temperaturas após um passo $p$ no tempo (após um intervalo de tempo igual a $\Delta t$ ) e essa multiplicação matricial nos leva a um vetor de termos independentes [C]. Logo, se acharmos a matriz inversa $\left[A^{-1}\right]$, sabemos então que nosso vetor $[T]=\left[A^{-1}\right][C]$, o que nos da o vetor temperatura após um intervalo de tempo $\Delta$ t. Repetindo esse processo teremos novos vetores $[\mathrm{C}]$ e novos vetores $[\mathrm{T}]$ ao longo do tempo a cada $\Delta \mathrm{t}$. Montou-se então uma planilha no Excel ${ }^{\circledR}$ para tal calculo.

A maior dificuldade é o calculo do coeficiente convectivo $h$, que aparece na equação (4) na Tabela 1. O cálculo de h envolve fórmulas e teorias complexas e o problema é agravado pelas condições extremamente variáveis na linha de produção. Para solucionar tal problema o $\mathrm{h}$ foi calculado de forma reversa. Para tal, foi feito uma termografia na área, onde a linha de produção foi dividida em pontos de interesse, como se vê na Figura 1 abaixo. Uma equipe especializada fez tomadas termográficas ao longo de 7 ciclos de laminações em tais pontos. As leituras médias da termografia podem ser vistas na Tabela 2 abaixo.

* Contribuição técnica ao $35^{\circ}$ Seminário de Balanços Energéticos Globais e Utilidades e $29^{\circ}$ Encontro de Produtores e Consumidores de Gases Industriais, 13 a 15 de agosto de 2014, São Paulo, SP, Brasil. 


\section{vallourec}

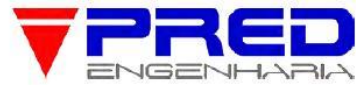

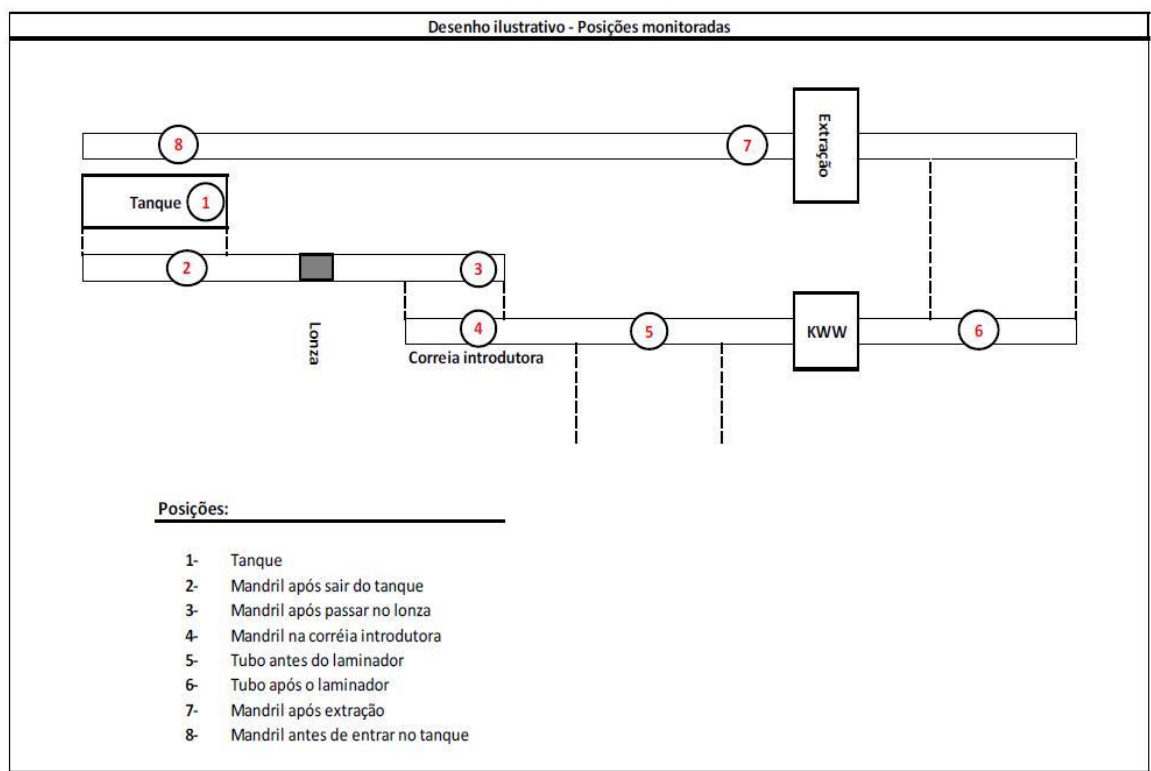

Figura 1. Pontos de tomada termográfica na linha de produção (O lubrificante é aplicado no ponto onde se lê Lonza).

Tabela 2. Dados do ensaio termográfico nos mandris

\begin{tabular}{lcccccccc}
\hline Ciclo & $\begin{array}{c}\text { Posição } \\
\mathbf{0 4}\end{array}$ & $\begin{array}{c}\text { Posição } \\
\mathbf{0 5}\end{array}$ & $\begin{array}{c}\text { Posição } \\
\mathbf{0 6}\end{array}$ & $\begin{array}{c}\text { Posição } \\
\mathbf{0 7}\end{array}$ & $\begin{array}{c}\text { Posição } \\
\mathbf{0 8}\end{array}$ & $\begin{array}{c}\text { Posição } \\
\mathbf{0 1}\end{array}$ & $\begin{array}{c}\text { Posição } \\
\mathbf{0 2}\end{array}$ & $\begin{array}{c}\text { Posição } \\
\mathbf{0 3}\end{array}$ \\
\hline 1 ciclo $^{2}$ & 26 & - & - & - & 153 & 34 & 62 & 70 \\
\hline $2^{\circ}$ ciclo & 65 & 1122 & 894 & 184 & 153 & 35 & 60 & 66 \\
\hline $3^{\circ}$ ciclo & 68 & 1095 & 894 & 206 & 160 & 37 & 69 & 80 \\
\hline $4^{\circ}$ ciclo & 84 & 1146 & 885 & 200 & 190 & 35 & 85 & 122 \\
\hline $5^{\circ}$ ciclo & 116 & - & 896 & 249 & 217 & 37 & 85 & 116 \\
\hline $6^{\circ}$ ciclo & 121 & 1160 & 897 & 241 & 234 & 38 & 76 & 100 \\
\hline $7^{\circ}$ ciclo & 137 & 1133 & 911 & 248 & 224 & 36 & 91 & - \\
\hline $8^{\circ}$ ciclo & 116 & & & & & & & \\
\hline
\end{tabular}

A partir da termografia, a linha de produção foi dividida em 4 casos de estudo considerados relevantes para a aplicação do MDF, sendo estes o contato do mandril com a lupa (contato), a mesa de rolos entre o fim do contato e a iminência da entrada do mandril no tanque de resfriamento $(C-T)$, o tanque de resfriamento (tanque), e a saída do tanque até a iminência do novo contato com a lupa, passando pela lubrificação e leito de resfriamento (Lonza).

Aplicou-se então o MDF em cada um dos casos, estimando-se um valor de $h$ inicialmente, para a evolução dos cálculos no MDF. Então, com a utilização da ferramenta "Atingir Meta" do $\operatorname{Excel}^{\circledR}$, seleciona-se a célula correspondente à temperatura superficial final do mandril, após o tempo total do mandril no referido caso, introduz-se o valor lido pela termografia e a ferramenta "Atingir Meta" faz o cálculo do coeficiente convectivo $\mathrm{h}$ equivalente para se atingir a temperatura lida.

Com o h calculado para cada caso nos vários ciclos, cria-se um histórico de coeficientes convectivos que evoluem com as passagens do mandril na linha de produção. Para validação de tal cálculo de $h$, calculou-se um $h$ médio para cada caso, e as temperaturas superficiais do mandril ao longo da linha de produção foram recalculadas com o $\mathrm{h}$ médio e confrontadas com as leituras termográficas. 


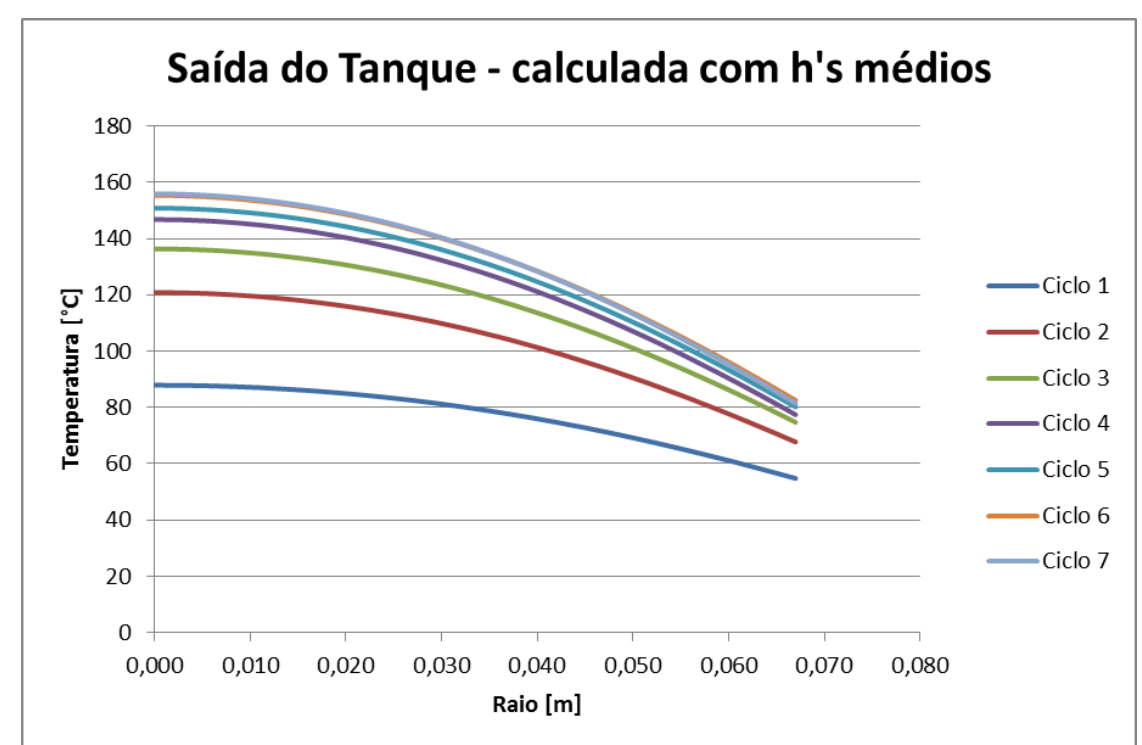

Figura 3. Perfis térmicos radiais do mandril após saída do tanque de resfriamento em ciclos de laminação. Perfis fruto do cálculo usando-se h's médios.

Nota-se claramente o núcleo do mandril apresentando temperaturas superiores às temperaturas superficiais. Acredita-se que devido a boa condutividade térmica do aço e a números de Biot (razão entre as resistência térmica interna de um sólido e a resistência térmica na camada-limite) pequenos encontrados nos cálculos, o calor cedido ao mandril pela lupa, tenha uma tendência a mover-se para o centro do mandril ao invés de ser transferido por convecção para o meio. Logo, acredita-se que nos primeiros ciclos de laminação, o calor tenda a se transferir para o centro do mandril ao invés de ser transferido para a água do lubrificante. A partir do $3 \stackrel{0}{\text { ciclo de }}$ laminação, quando empiricamente é observada a evaporação devida da água do lubrificante, acredita-se que o núcleo do mandril já tenha absorvido calor o suficiente e o processo tenda a entrar em regime permanente, chama-se a atenção para o fato das curvas a partir do $4^{\circ}$ ciclo estarem mais próximas na Figura 2 e as mesmas curvas praticamente sobrepostas na Figura 3. Quando o processo de laminação entra em regime permanente, o núcleo do mandril deixa de roubar calor da periferia do mesmo e começa a funcionar como fonte de calor à superfície, que transfere esse calor à água do lubrificante, proporcionando assim a evaporação da mesma. Essa teoria é confirmada quando se observa as leituras da termografia. Em vários pontos onde era de se esperar que a temperatura superficial do mandril diminuísse, ela aumenta. Como observado na Tabela 2, isso acontece na maioria das transições da posição 2 para a posição 3 e da posição 3 para a posição 4 . Essas posições se encontram logo após 0 tanque de resfriamento que resfria 0 mandril superficialmente, mas não consegue resfriar tanto, no tempo que o mesmo permanece no tanque, o núcleo do mandril, que se encontra mais quente que a superfície.

De acordo com os gráficos das Figuras 2 e 3 acima e os cálculos realizados, têm-se a quantidade de energia necessária, calculada considerando os coeficientes convectivos encontrados da forma reversa e médios, a ser cedida ao mandril por um método de pré-aquecimento considerado.

Tabela 3. Energia do mandril no início do 4ำ ciclo de laminação

\begin{tabular}{lcc}
\hline Método de Cálculo & Energia [J] & Potência [W] \\
\hline h reverso & 83.565 .564 & 3.798 .435 \\
\hline h's médios & 88.973 .943 & 3.968 .718 \\
\hline
\end{tabular}

* Contribuição técnica ao $35^{\circ}$ Seminário de Balanços Energéticos Globais e Utilidades e $29^{\circ}$ Encontro de Produtores e Consumidores de Gases Industriais, 13 a 15 de agosto de 2014, São Paulo, SP, Brasil. 


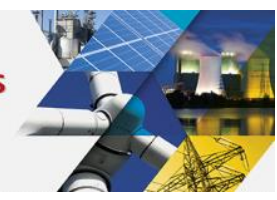

Nota-se na Tabela 3 acima, que ambos os métodos apresentaram resultados parecidos. Lembrando que o valor considerado foi o valor de energia do mandril calculado ao final do $3^{\circ}$ ciclo de laminação, prestes a entrar no $4^{\circ}$. Se considerarmos um forno de indução, ou um forno convectivo como método de pré-aquecimento, e considerarmos que o mandril passa por esse forno a velocidade média de $1 \mathrm{~m} / \mathrm{s}$ (velocidade da linha de produção) e considerarmos também seu comprimento aproximadamente 22 metros, logo esse forno deveria ter uma potência de aproximadamente $4 \mathrm{MW}$ considerando um rendimento de $100 \%$, esse número também é mostrado na Tabela 3.

\subsection{Cálculos dos Coeficientes Convectivos de Forma Reversa, Coeficientes Convectivos Médios e a Natureza Funcional do Coeficiente Convectivo}

$\mathrm{Na}$ Tabela 4 a seguir, têm-se os coeficientes convectivos calculados de forma reversa por ciclo e caso de estudo e também os coeficientes médios para cada caso.

Tabela 4. Coeficientes convectivos

\begin{tabular}{|c|c|c|}
\hline Ciclo & Caso & $\mathrm{h}$ reverso \\
\hline 10 & Contato & 40,2593 \\
\hline $1^{0}$ & C-T & $-106,661$ \\
\hline $1^{0}$ & Tanque & 1821,094 \\
\hline $1^{0}$ & Lonza & 556,5629 \\
\hline $2^{0}$ & Contato & 396,3325 \\
\hline $2^{0}$ & C-T & 356,0688 \\
\hline $2^{0}$ & Tanque & 3028,856 \\
\hline $2^{0}$ & Lonza & 725,2374 \\
\hline $3^{\circ}$ & Contato & 171,4981 \\
\hline $3^{\circ}$ & C-T & 512,3448 \\
\hline $3^{\circ}$ & Tanque & 2493,639 \\
\hline $3^{\circ}$ & Lonza & 418,3894 \\
\hline $4^{\circ}$ & Contato & 415,6975 \\
\hline $4^{\circ}$ & C-T & $-64,9209$ \\
\hline $4^{\circ}$ & Tanque & 1632,303 \\
\hline $4^{\circ}$ & Lonza & 70,6405 \\
\hline $5^{\circ}$ & Contato & 110,8985 \\
\hline $5^{\circ}$ & C-T & 117,5792 \\
\hline $5^{\circ}$ & Tanque & 2253,653 \\
\hline $5^{\circ}$ & Lonza & 154,1273 \\
\hline $6^{\circ}$ & Contato & 277,244 \\
\hline $6^{\circ}$ & C-T & $-142,522$ \\
\hline $6^{\circ}$ & Tanque & 3082,386 \\
\hline $6^{-0}$ & Lonza & $-61,2262$ \\
\hline $7^{\circ}$ & Contato & 247,3841 \\
\hline $7^{0}$ & C-T & 93,97663 \\
\hline $7^{0}$ & Tanque & 2068,052 \\
\hline $7^{0}$ & Lonza & 318,5064 \\
\hline Média & Caso & h médio \\
\hline Média & Contato & 237,0449 \\
\hline Média & C-T & 109,4093 \\
\hline Média & Tanque & 2339,998 \\
\hline Média & Lonza & 311,7482 \\
\hline
\end{tabular}

* Contribuição técnica ao $35^{\circ}$ Seminário de Balanços Energéticos Globais e Utilidades e $29^{\circ}$ Encontro de Produtores e Consumidores de Gases Industriais, 13 a 15 de agosto de 2014, São Paulo, SP, Brasil. 


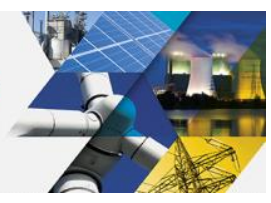

Nota-se na Tabela 4 acima, duas observações. A primeira que os coeficientes de um mesmo caso variam consideravelmente de um ciclo para o outro nos primeiros ciclos. A segunda que existem 4 coeficientes convectivos negativos.

Acredita-se que por se tratar de um modelo matemático numérico, o fato dos coeficientes convectivos variarem seria o modelo se ajustando. O que pode comprovar isso seria que os coeficientes convectivos variam mais nos primeiros ciclos, convergindo para a média no último ciclo estudado. Acredita-se que se fosse estudado um número maior de ciclos, a convergência dos coeficientes convectivos seria maior.

Acredita-se também que os coeficientes convectivos negativos sejam uma autocorreção do modelo numérico. Ao usar a ferramenta "Atingir Meta" o coeficiente convectivo também funciona como uma constante de correção do cálculo do modelo. Como os cálculos foram feitos usando tempos médios para cada caso, e na linha de produção esses tempos variam consideravelmente ao longo da laminação, o h negativo seria uma correção a esse fator além de outros inúmeros fatores que mudam sempre durante o processo. Por exemplo, o modelo considera que o mandril em determinado ciclo ficou em contato com a lupa determinado tempo em segundos, quando na realidade nesse determinado ciclo na produção ele pode ter ficado alguns segundos a mais em contato com a lupa. Logo, no estudo de caso seguinte, apareceria um h negativo "criando" calor no mandril para compensar esse efeito.

Finalmente, é interessante quando plota-se o gráfico do valor de $\mathrm{h}$ por posição na linha de produção, como na Figura 4 abaixo. Na figura tem-se o valor de h no eixo vertical e o sua posição no eixo horizontal, sendo que a posição foi marcada como $11,12,13,14,21, \ldots, 64,71,72,73,74$, onde o primeiro número representa o ciclo de laminação e o segundo a posição na linha.

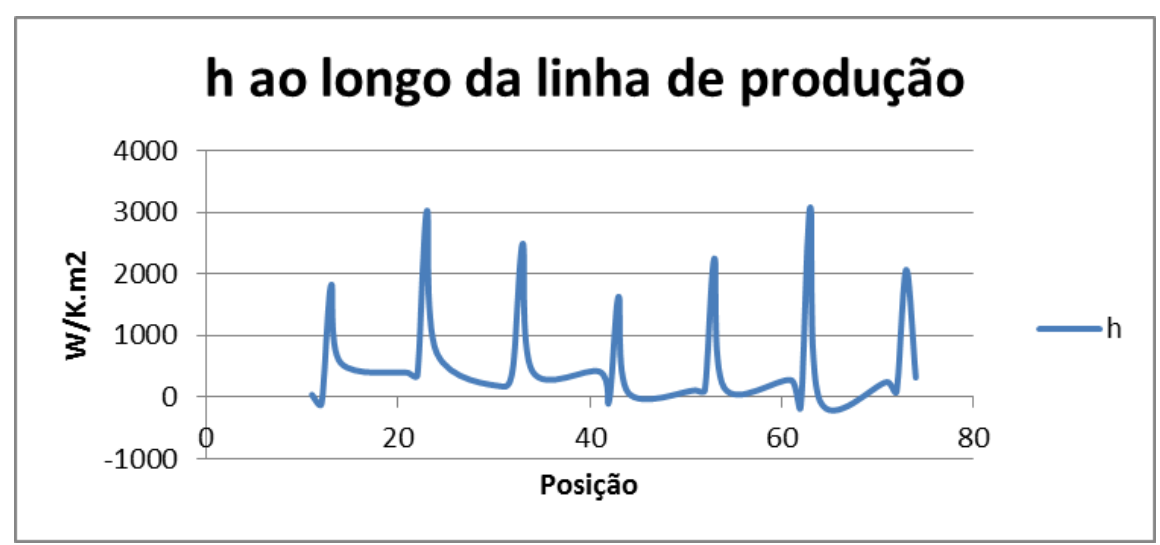

Figura 4. Valor do coeficiente convectivo ao longo dos ciclos de laminação.

Observa-se no gráfico da Figura 4 claramente um padrão para o coeficiente convectivo h.

\subsection{Cálculo das Temperaturas pelos Coeficientes Convectivos Médios}

$\mathrm{Na}$ Tabela 5, tem-se a leitura média da termografia por posição por ciclo, junto com as respectivas leituras mínima e máxima, assim como o desvio padrão calculado e a temperatura calculada pelo MDF usando os coeficientes convectivos médios. 
Tabela 5. Temperaturas lidas pela termografia e temperaturas calculadas pelo MDF

\begin{tabular}{|c|c|c|c|c|c|c|}
\hline CICLO & POSIÇÃO & MIN & MAX & MED & $\begin{array}{c}\text { DESVIO } \\
\text { PADRÃO }\end{array}$ & MDF \\
\hline 1 & 7 & ND & ND & ND & ND & 162,0 \\
\hline 1 & 8 & 126 & 186 & 153 & 30,05 & 133,3 \\
\hline 1 & 2 & 59 & 65 & 62 & 3,00 & 54,8 \\
\hline 1 & 4 & 50 & 70 & 65 & 10,41 & 65,8 \\
\hline 2 & 7 & 123 & 274 & 184 & 75,96 & 196,4 \\
\hline 2 & 8 & 111 & 198 & 153 & 43,51 & 169,6 \\
\hline 2 & 2 & 49 & 68 & 60 & 9,54 & 67,7 \\
\hline 2 & 4 & 56 & 71 & 68 & 7,94 & 85,7 \\
\hline 3 & 7 & 126 & 313 & 206 & 93,82 & 210,5 \\
\hline 3 & 8 & 141 & 212 & 160 & 36,76 & 185,4 \\
\hline 3 & 2 & 59 & 73 & 69 & 7,21 & 74,7 \\
\hline 3 & 4 & 74 & 88 & 84 & 7,21 & 95,3 \\
\hline 4 & 7 & 143 & 274 & 200 & 65,68 & 225,2 \\
\hline 4 & 8 & 151 & 225 & 190 & 37,02 & 199,3 \\
\hline 4 & 2 & 71 & 97 & 85 & 13,01 & 77,4 \\
\hline 4 & 4 & 93 & 123 & 116 & 15,70 & 101,2 \\
\hline 5 & 7 & 161 & 339 & 249 & 89,00 & 227,5 \\
\hline 5 & 8 & 172 & 251 & 217 & 39,63 & 202,5 \\
\hline 5 & 2 & 72 & 98 & 85 & 13,00 & 80,2 \\
\hline 5 & 4 & 96 & 130 & 121 & 17,62 & 104,0 \\
\hline 6 & 7 & 170 & 323 & 241 & 76,57 & 234,6 \\
\hline 6 & 8 & 186 & 267 & 234 & 40,73 & 208,7 \\
\hline 6 & 2 & 65 & 88 & 76 & 11,50 & 82,5 \\
\hline 6 & 4 & 119 & 147 & 137 & 14,19 & 106,9 \\
\hline 7 & 7 & 164 & 356 & 248 & 96,25 & 233,8 \\
\hline 7 & 8 & 195 & 260 & 224 & 32,56 & 208,8 \\
\hline 7 & 2 & 72 & 97 & 91 & 13,05 & 81,5 \\
\hline 7 & 4 & 102 & 126 & 116 & 12,06 & 106,9 \\
\hline
\end{tabular}

Nota-se na Tabela 5 acima, que apenas 5 temperaturas (15,15\%) calculadas pelo MDF encontram-se fora do desvio padrão dentre as 28 calculadas. Dessas 5 temperaturas fora do desvio padrão, duas foram medidas pouco tempo antes de pequenas paradas na linha de produção, o que afeta o modelo, visto que os tempos de processo considerados para o cálculo não levaram em consideração as paradas.

\subsubsection{Teste estatístico para comparação das temperaturas calculadas com os coeficientes convectivos médios e as leituras termográficas}

Para a comparação das temperaturas calculadas pelo MDF, usando-se os coeficientes convectivos médios com as temperaturas lidas na termografia, usou-se o método estatístico do teste de hipóteses do tipo t pareado. No teste de hipóteses foi usado um nível de confiança de $95 \%$ e considerou-se como hipótese nula que a leitura média da termografia é igual ao valor calculado pelo MDF e como hipótese alternativa que os dois valores eram diferentes (teste bi-lateral). Na Tabela 6, assim como nas Figuras 5 e 6 abaixo, encontra-se o resultado do teste de hipóteses.

* Contribuição técnica ao $35^{\circ}$ Seminário de Balanços Energéticos Globais e Utilidades e 29० Encontro de Produtores e Consumidores de Gases Industriais, 13 a 15 de agosto de 2014 , São Paulo, SP, Brasil. 


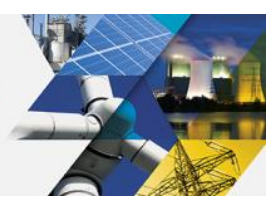

Tabela 6. Teste de hipóteses t pareado

\begin{tabular}{lcccc}
\hline Valor & N & Média & $\begin{array}{c}\text { Desvio } \\
\text { Padrão }\end{array}$ & $\begin{array}{c}\text { Média do } \\
\text { Erro Padrão }\end{array}$ \\
\hline Termografia & 27 & 144,2 & 66,1 & 12,7 \\
\hline MDF & 27 & 141,5 & 64,2 & 12,3 \\
\hline Diferença & 27 & 2,73 & 15,30 & 2,94 \\
\hline
\end{tabular}

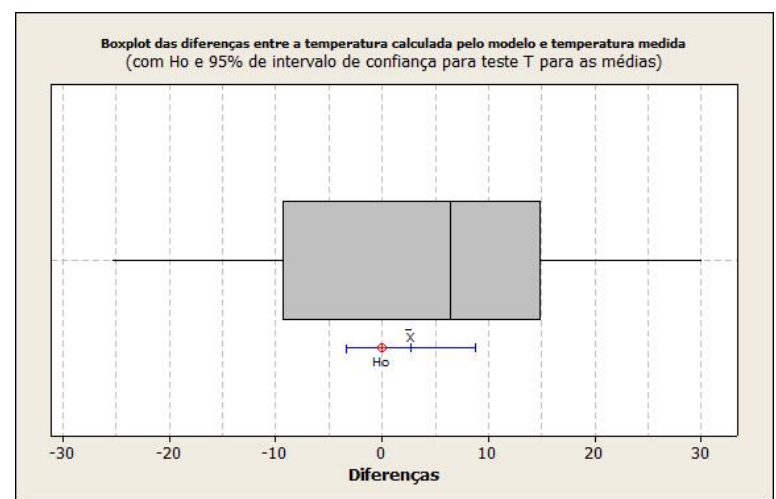

Figura 5. Boxplot das diferenças entre a temperatura calculada pelo modelo e temperatura medida.

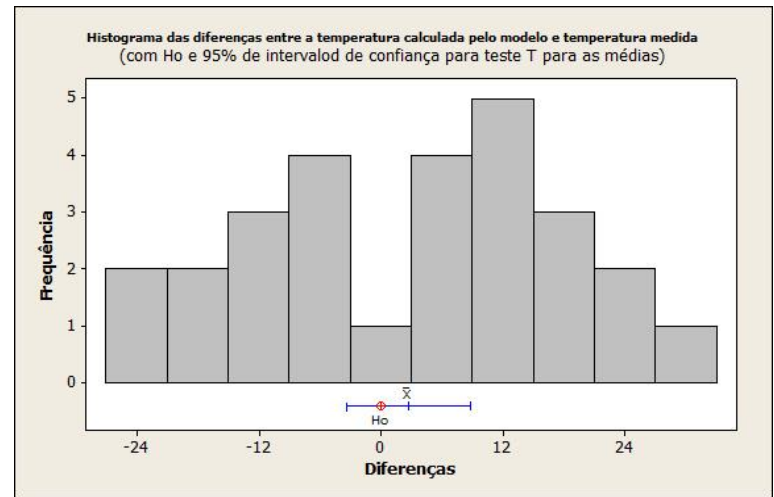

Figura 6. Histograma das diferenças entre a temperatura calculada pelo modelo e temperatura medida.

Segundo o teste de hipóteses t pareado, o intervalo de confiança de $95 \%$ da diferença das médias é $(-3,32 ; 8,78)$, nota-se que o intervalo contém o 0,00. Logo, segundo o teste de hipóteses, não há evidencias para refutar o modelo matemático.

\section{CONCLUSÃO}

Devido ao núcleo do mandril demandar uma grande quantidade de energia para se aquecer antes do mandril começar a liberar energia para o ambiente e a linha de produção ter um ritmo rápido, é necessário um método de pré-aquecimento que seja capaz de fornecer uma grande potência. É importante lembrar que a superfície do mandril não deve estar acima de $100^{\circ} \mathrm{C}$ ao ser lubrificada uma vez que isso levaria a formação de bolhas, prejudicando assim a camada de lubrificante. Logo, é importante considerar esse fato no projeto de um sistema de pré-aquecimento de mandris, para que o núcleo tenha tempo hábil para absorver o calor e a superfície não atinja temperaturas elevadas.

Acredita-se que o modelo matemático obteve sucesso em prever os perfis térmicos do mandril ao longo da linha de produção. No entanto, o modelo ainda pode ser melhorado e acredita-se que ele ainda é sensível a paradas e outros fenômenos que podem acontecer na linha de produção. Para trabalhos futuros seria interessante 
investigar, de posse de mais dados e mais estudos termográficos, o comportamento do coeficiente convectivo $h$ na linha de produção. Realizando mais testes para vários calibres de mandris e diâmetros das lupas laminadas, e utilizando-se de métodos estatísticos mais avançados seria possível criar um modelo matemático mais preciso que pudesse prever o comportamento de $\mathrm{h}$ com mais exatidão ao longo da linha de produção.

Este estudo do coeficiente convectivo é de grande importância, pois o mesmo modelo matemático teria grande valia se usado para a implementação de um sistema de controle para qualquer que seja o método de pré-aquecimento escolhido para o mandril. Não só seria útil para controle e automatização de um sistema de pré-aquecimento como também poderia ser útil para o maior controle de outras partes da linha de produção. Chama-se a atenção para o tanque de resfriamento, que tem serventia depois de um grande ciclo de laminações, para impedir que o mandril sobre-aqueça e leve a água do lubrificante a borbulhar quando em contato com sua superfície. No entanto, o tanque de resfriamento não é necessário no início do processo, nos primeiros ciclos de laminação, quando ele diminui a eficiência energética da linha. Uma alternativa ao tanque seriam chuveiros para o resfriamento do mandril, e então o mesmo modelo matemático seria útil também para a implantação de um sistema de controle para a vazão de água por exemplo.

\section{REFERÊNCIAS}

1 Incropera FP, DeWitt DP. Introduction to Heat Transfer. 2nd edition. Singapore: John Wiley \& Sons, Inc.; 1990. 